\title{
A New Support Structure for High Field Magnets.
}

\author{
P.A. Bish, S. Caspi, D.R. Dietderich, S.A. Gourlay, R.R. Hafalia, R. Hannaford, A.F. Lietzke, N. \\ Liggins, A.D. McInturff, G.L. Sabbi, R.M. Scanlan, J. O’Neill, J.H Swanson
}

\begin{abstract}
${ }^{1}$ Abstract--Pre-stress of superconducting magnets can be applied directly through the magnet yoke structure. We have replaced the collar functionality in our 14 Tesla $R \& D N_{3} S n$ dipole magnets with an assembly procedure based on an aluminum shell and bladders. Bladders, placed between the coil pack and surrounding yoke inside the shell, are pressurized up to $10 \mathrm{ksi}[70 \mathrm{MPa}]$ to create an interference gap. Keys placed into the interference gap replace the bladder functionality. Following the assembly, the bladders are deflated and removed. Strain gauges mounted directly on the shell are used to monitor the stress of the entire magnet structure, thereby providing a high degree of pre-stress control without the need for high tolerances. During assembly, a force of $8.2 \times 10^{5} \mathrm{lbs} / \mathrm{ft}$ [12 MN/m] is generated by the bladders and the stress in the 1.57 " [40mm] aluminum shell reaches $20.3 \mathrm{ksi}$ [140 MPa]. During cool-down the thermal expansion difference between shell and yoke generates an additional compressive force of $6.85 \times 10^{5} \mathrm{lbs} / \mathrm{ft}$ [10 $\mathrm{MN} / \mathrm{m}$ ], corresponding to a final stress in the shell of $39.2 \mathrm{ksi}$ [270 MPa]. Pre-stress conditions are sufficient for $16 \mathrm{~T}$ before the coils separate at the bore. Bladders have now been used in the assembly and disassembly of two $14 \mathrm{~T}$ magnets. This paper describes the magnet structure, assembly procedure and test results.
\end{abstract}

Index Terms--bladder, high-field, $\mathrm{Nb}_{3} \mathrm{Sn}$, structure, superconducting

\section{INTRODUCTION}

$\mathrm{L}$ ow field and high field superconducting magnets are being considered as possible candidates for accelerator rings beyond the LHC. Next generation high energy physics experiments will require the use of high energy machines such as the Very Large Hadron Collider and muon colliders. The Superconducting Magnet Program at LBNL is focused on the high field option with fields approaching 14 Tesla and beyond. We believe that the high field option will have a direct impact on reducing the ring size and thereby reducing its cost. Developing the technology of a cost effective high field magnet is a key element in our program.

Fields above 10 Tesla require the use of A15 compounds that are brittle and strain sensitive. Unfortunately, high field

Manuscript received September 24, 2001. This was supported by the Director, Office of Energy Research, Office of High Energy and Nuclear Physics, High Energy Physics Division, U. S. Department of Energy, under Contract No. DE-AC03--76SF00098.

R.R. Hafalia is with the Lawrence Berkeley National Lab, Berkeley, CA 94720 USA (telephone: 510-486-5712, e-mail: rrhafalia@1bl.gov. involves large forces and requires higher pre-stress. For the foreseeable future, $\mathrm{Nb}_{3} \mathrm{Sn}$ is the only practical high-field conductor available. The combination of large forces and brittle conductor makes the design and assembly of such magnets a real challenge (Fig. 1).

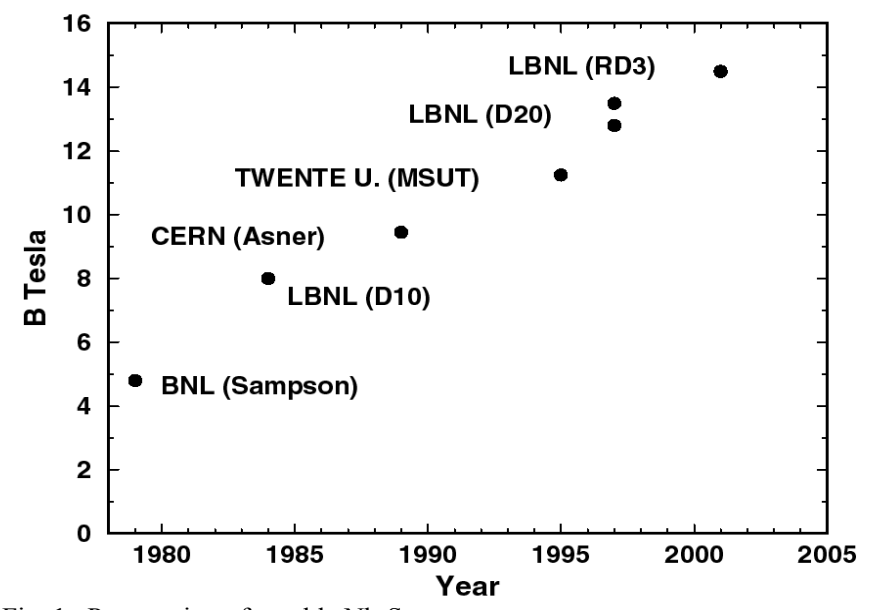

Fig. 1, Progression of notable $\mathrm{Nb}_{3} \mathrm{Sn}$ magnets.

We have designed, fabricated and tested a series of magnets based on the "Common Coil" configuration. Following the successful test of magnet RD-2 and RT-1 (6 and 12 Tesla, respectively), we recently have successfully tested magnet RD-3 (Fig. 2) - arriving at a record dipole field of 14.7 Tesla. Past work can be found in Ref.'s [1][2][3].

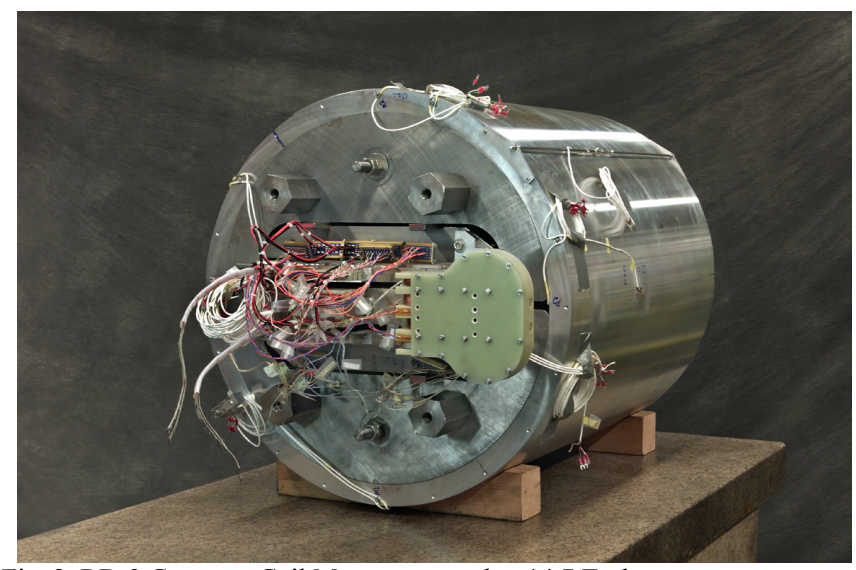

Fig. 2, RD-3 Common Coil Magnet - tested to 14.7 Tesla 


\section{CONCEPT OF OPERATION}

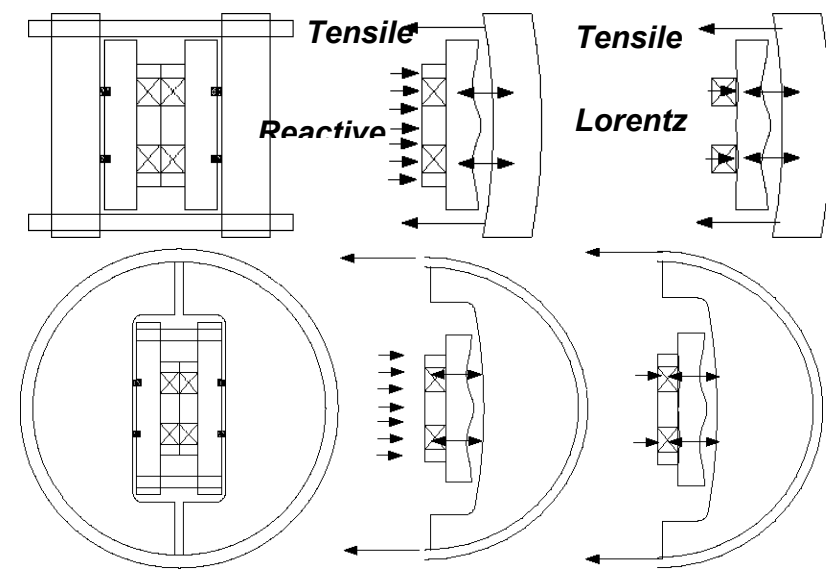

Fig. 3, Force Diagram: RT-1 Magnet Loading Design (top) vs. RD-3 Loading Design (bottom)

The large Lorentz forces make the use of a cantilever structure (Fig. 3, top) too soft. That effect was demonstrated in magnet RT-1 where the structure allowed the coil halves to separate more than $1.5 \mathrm{~mm}$ at $12 \mathrm{~T}$. The use of a circular shell is more efficient in providing pre-stress that can effectively prevent the coils from separating. The force balance between shell and coils takes place in several steps. Initially the shell pre-stress is set to $20.3 \mathrm{ksi}$ [ $140 \mathrm{MPa}$ ] by the bladders and keys. During cool-down the stress increases to $39.2 \mathrm{ksi}[270 \mathrm{MPa}]$ and remains unchanged during operation. The force on the shell is reacted by the force between the symmetrical halves of the magnet (Fig. 3 bottom). We expect most of the reactive force to be carried by the iron pole. The Lorentz force loads the coils and unloads the bore, posts and side rails. The coil modules will separate only after the Lorentz force overcomes the reactive force, which is not expected to happen below $16 \mathrm{~T}$ - well above the short-sample field for RD-3.

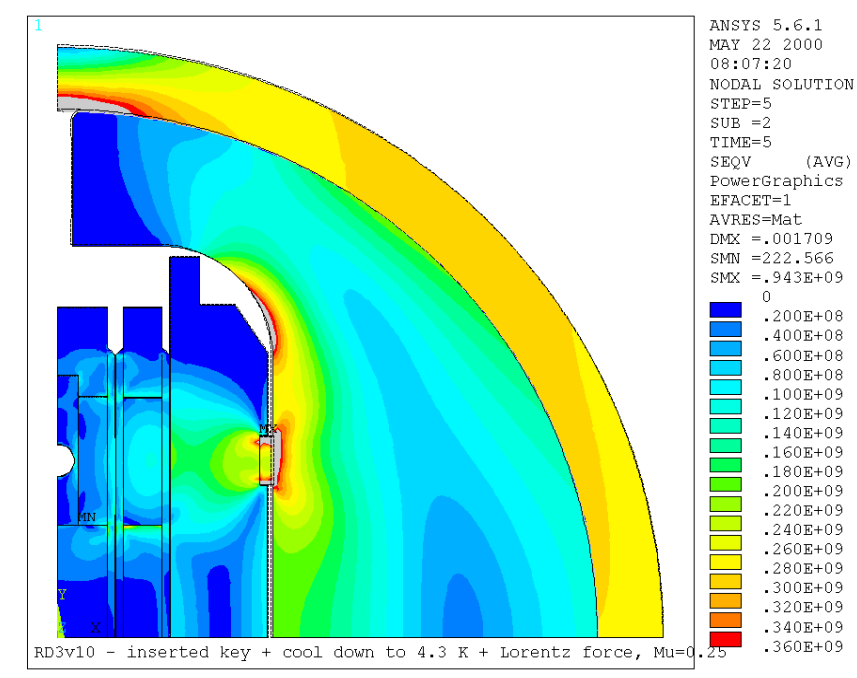

Fig. 4, ANSYS analyses at $4.3 \mathrm{~K}$ and magnet at maximum Lorentz forces.
The integrated double bore Lorentz force at $16 \mathrm{~T}$ is $\mathrm{F}_{\mathrm{x}}=1.5 \times 10^{6} \mathrm{lbs} / \mathrm{ft}[22 \mathrm{MN} / \mathrm{m}], \mathrm{F}_{\mathrm{y}}=-2.1 \times 10^{5} \mathrm{lbs} / \mathrm{ft}[-3.0 \mathrm{MN} / \mathrm{m}]$ and $\mathrm{F}_{\mathrm{z}}=1.57 \times 10^{5} \mathrm{lbs}[700 \mathrm{KN}]$. The program ANSYS was used to calculate the magnetic forces and perform the structural analysis (Fig. 4). The load case progression followed the steps of assembly, cool-down and $16 \mathrm{~T}$ Lorentz load and was later confirmed by strain gauge measurements.

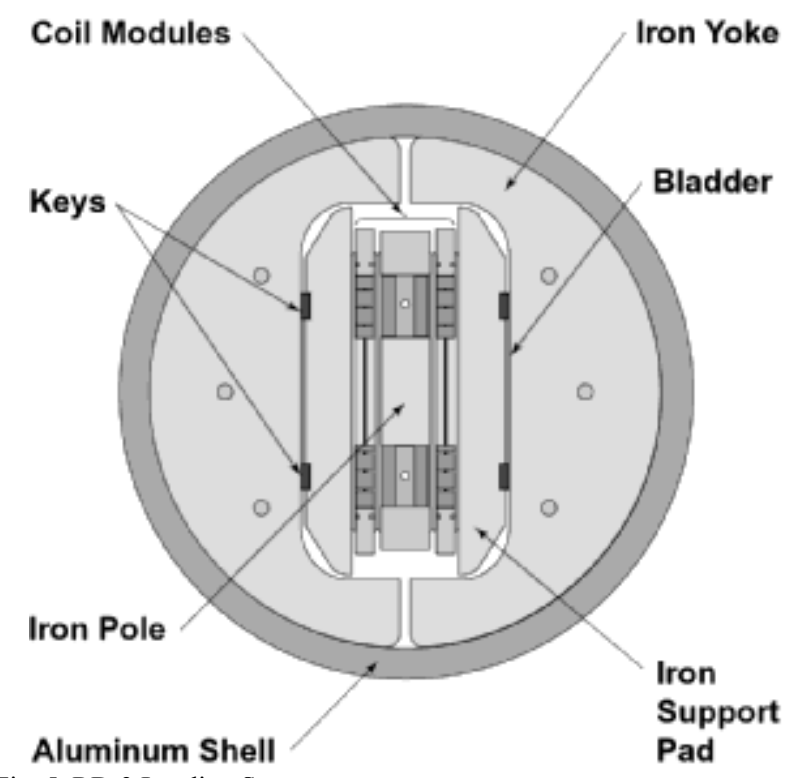

Fig. 5, RD-3 Loading Structure components.

\section{LOADING STRUCTURE DESIGN}

\section{A. Components}

The basic loading structure consists of the following components - a pair of ferrous steel "yoke-stack" assemblies; a single aluminum cylindrical "shell"; a set of 4 interference keys (hardened steel bars); and the magnet coil-pack itself (Fig. 5). A "temporary", but essential component in the assembly are the bladders. The bladders used in the assembly process provide the primary force that spreads the yoke stacks apart within the cylindrical shell, thus stretching the shell to provide the compressive force that preloads the coil-pack. Once the structure is "locked" in place with the interference keys, the bladders are deflated and removed.

\section{B. Shell}

The shell provides the ultimate preload on the magnet coilpack. During cool-down, it essentially doubles its preload on the coil-pack, through thermal contraction. The design preload at $4.3 \mathrm{~K}$ is high enough to maintain a stable structure up to a 16 Tesla field.

The shell material used is a 2219-T852, aluminum alloy tube forging - selected for high resistance to crack propagation. To further address the crack propagation concern, a material quality specification similar to ASTM B247 was called out. An ultrasonic inspection specification (ASTM 8594, Class A) was also called out. The shell finish dimensions are: OD of 29.134" [740 mm]; ID of 25.984" [660 mm] and length of 34.481 " $[875.82 \mathrm{~mm}]$. The ID surface finish was specified at 
32 micro-inches. The final shell weight was $450 \mathrm{lbs}$ [204 kg].

The shell instrumentation consisted of full-bridged resistive strain gages - temperature compensated; 8 in the azimuthal direction (symmetrically placed inside and outside surfaces) and 4 in the axial direction.

\section{Iron Yoke Laminations}

The steel yokes provide the means of transferring the preload forces from the shell to the coil-pack via the keys. Full contact between the yoke-stacks and the shell is required to equally distribute the compressive forces from the stretched shell, through the keys to the coils. The laminations are made of A-36 Structural Steel plate ground to a thickness of $2.000 "$ " $50.80 \mathrm{~mm}$ ]. The profile was rough-cut to within 0.063 " [1.6 mm] of finish dimensions by water-jet cutter. This process was utilized to minimize machining stresses and process time. Final machining, to a surface finish of 32 micro-inches, was conventionally done on 2-axis $\mathrm{N}-\mathrm{C}$ milling machine with a special, multi-carbide tipped cutter. Each lamination half weighed about $90 \mathrm{lbs}$. [ 41 kg]. Alignment of the cylindrical surfaces of the laminations as well as the internal planar surfaces were critical. Each of the yoke stacks were pre-assembled with 3, 1" diameter, 304 stainless steel rods with threaded ends. Eighteen laminations were stacked and pre-assembled by torquing nuts on each of the 3 rods to $125 \mathrm{ft}-\mathrm{lbs}$. [170 N-m]. Before assembly, each lamination was coated with dry-lubricant (graphite powder). Each of the 2 stacks weighed $1650 \mathrm{lbs}[748 \mathrm{~kg}]$.

\section{Bladders}

The bladders are essential components in the assembly process by virtue of their ability to exert the maximum amount of force and stroke relative to their thin cross-section. Extensive pressure testing of various welding processes and procedures was performed to arrive at the present, nominal design. Bladders were made of two 304 stainless steel sheets, each 0.010 " [0.254 mm]-thick, which were N-C laser welded together around the perimeter. The feed tube is also laser welded at the corner. The main bladders are rectangular, 34.48 " x 7.25" [875.8 $\mathrm{mm} \times 184.2 \mathrm{~mm}$ ].

A smaller set of "auxiliary" bladders were also used for additional pressure. They were installed in 4 places, just outboard of each interference key. These were also rectangular, 34.48" x 1.79" [875.8 $\mathrm{mm}$ x $45.5 \mathrm{~mm}$ ].

\section{Assembly}

\section{A. Loading Structure Pre-Assembly}

A special hydraulic actuator rig was fabricated to initially spread the yoke-stacks apart against the ID surface of the aluminum shell. The rig consisted of 20 Enerpac "pancake" hydraulic actuators manifolded together on one of 2, 3" [76.2 $\mathrm{mm}$ ]-thick aluminum plates. This assembly was "sandwiched" between the 2 yoke-stacks and temporarily banded together so that it would fit inside the shell ID.

Both the yoke-stack outer surfaces and the shell's internal surface were re-coated with dry lubricant. The shell was then lifted over and lowered around the yoke-stack/actuator assembly. The shell was blocked and set in place centering it over the length of the yoke-stacks.

Monitoring the shell stresses by the shell strain gages, the hydraulic actuator assembly was gradually pressurized to $10,000 \mathrm{psi}[70 \mathrm{MPa}$ - forcing the yoke-stacks against the shell ID surface. Temporary spacer bars were slid into the gaps between the yoke-stacks to lock the stacks against the shell when the hydraulic pressure was released. After the hydraulic cylinders were removed, the shell and yoke-stacks could be handled as one unit. This process was required only on the initial magnet assembly. The whole assembly weighed $\sim 3800 \mathrm{lbs}[1723 \mathrm{~kg}]$.

\section{B. Coil-Pack Pre-Assembly}

The 2 outer coil modules (from RT-1), with the RD-3 inner coil module in between were aligned with 3 common, insulated pins through each module's island pole. The modules and pads were electrically isolated from each other by $0.010 "$ " $0.25 \mathrm{~mm}]$-thick NEMA G-10 sheets. The 3 modules were pre-compressed between 2 iron support pads by $20,0.375$ " $[9.5 \mathrm{~mm}]$ diameter bolts torqued to $40 \mathrm{ft}-1 \mathrm{bs}$ [ 54 $\mathrm{N}-\mathrm{m}$ ] - an equivalent bladder pressure of $580 \mathrm{psi}$ [4 MPa]. Four of these bolts were instrumented with strain gages to monitor bolt tension. Two devices were employed to monitor coil-to-coil separation. A strain-gage flexure was installed, mid-length along the magnet, connecting the two iron support pads and a commercial gap-measuring device, using a photooptic proximity principle, was installed at the end of the coil pack on the pad ends.

\section{Loading Structure/Coil-Pack Assembly}

After shell/yoke-stack assembly was placed in a horizontal position, the pre-assembled coil-pack, weighing $\sim 1800 \mathrm{lbs}$ $[817 \mathrm{~kg}]$, was slid into the cavity between the yoke-stacks and centered within the length of the loading structure.

Hardened steel keys were slid in to support the coil-pack off the bottom of the loading structure cavity. The keys were sized to leave an equal gap above and below the coil-pack for bladders and shims. The initial key thickness for this installation was 0.375 " [9.525 mm].

The main bladders were slid into place along with several "slip-shims" to completely fill the gap between the coil pack and the yoke-stacks. The slip shims were made to protrude out the back of the coil-pack with provisions for pulling them out after preload was attained. The slip-shims also "shielded" the bladders from surface irregularities from the yoke-stack laminations. Note that the bladders were constructed of 2, 0.010 " [0.254mm]-thick laser-welded sheets and pressurized to around $8000 \mathrm{psi}$ [55 MPa]. Each of the main bladders were 34.48 " x 7.25 " [875.8mm x $184.2 \mathrm{~mm}$ ]. At $8000 \mathrm{psi}$, the force generated by this area was almost 2,000,000 lbs. [ 9.0 MN].

The bladders were then pressurized with water from a 30,000 psi [207 MPa]-capacity, air-operated, hydraulic pump 
system. Each bladder line was also controlled with a shut-off valve from a common manifold so that up to 6 bladders could be differentially pressurized. Magnetically mounted dial indicators were placed at each end of the yoke-stacks. The dial indicator readings, along with other electronically recorded data, namely bladder pressure and strain gage signals from the shell and bolt gages, gave a comprehensive picture of what was taking place in the assembly.

The bladders were incrementally pressurized together until the target room-temperature shell strain was attained. During the pauses at each increment, thicker keys and shims were inserted at all four places to fill in the increasing key-gaps.

\section{Reduced Test Data \& Summary}

The magnet performed better than expected, reaching a measured central field of $14.7 \mathrm{~T}$. At the conductor, the field exceeded 15.3 $\mathrm{T}$ at a current of $10880 \mathrm{~A}$ (Fig. 6). The expected short-sample current density at $12 \mathrm{~T}$ was also exceeded by $6 \%$ corresponding to $2200 \mathrm{~A} / \mathrm{mm}^{2}$. The first quench was at $8 \mathrm{~T}$, followed by 22 training quenches, raising the field to $14 \mathrm{~T}$. It took an additional 22 quenches for the magnet to reach its final field value. A thermal cycle did not result in any retraining.

Shell and bolt strains were recorded by the strain gages through the entire assembly process and magnet test,. Azimuthal and axial strain of the shell have been converted into stress and plotted against time in Figures $7 \& 8$. The azimuthal stress doubled during cool-down and, regardless of field, remained unchanged during the entire test. The axial stress was minimal during assembly (indicating slippage between the shell and the iron yoke) but had substantially increased during cool-down (indicating the shell has locked onto the iron yoke). The lack of creep and the elastic behavior of the magnet are evident.

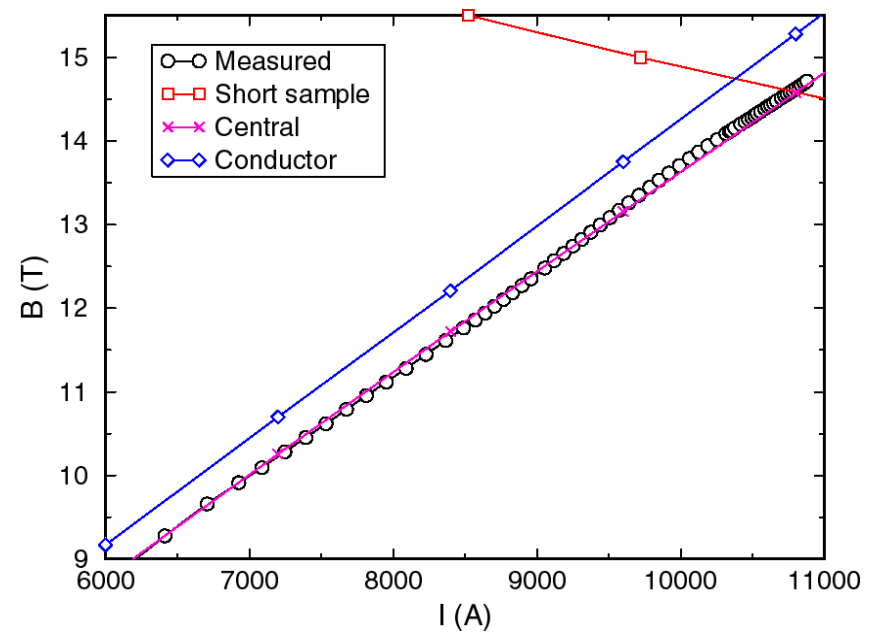

Fig. 6, RD-3 measured and calculated central field load line. The final field exceeded the maximum short-sample prediction.

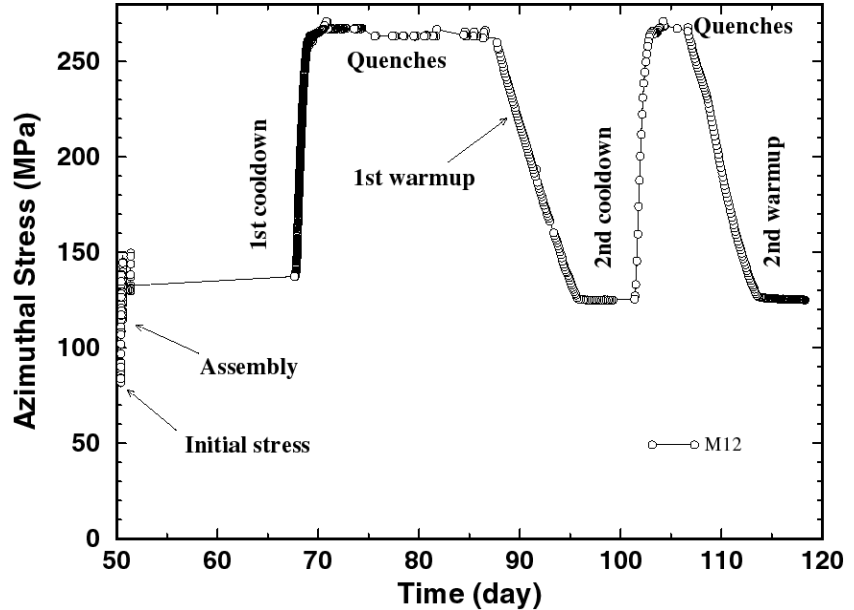

Fig. 7, Azimuthal Stress in the Shell vs. time.

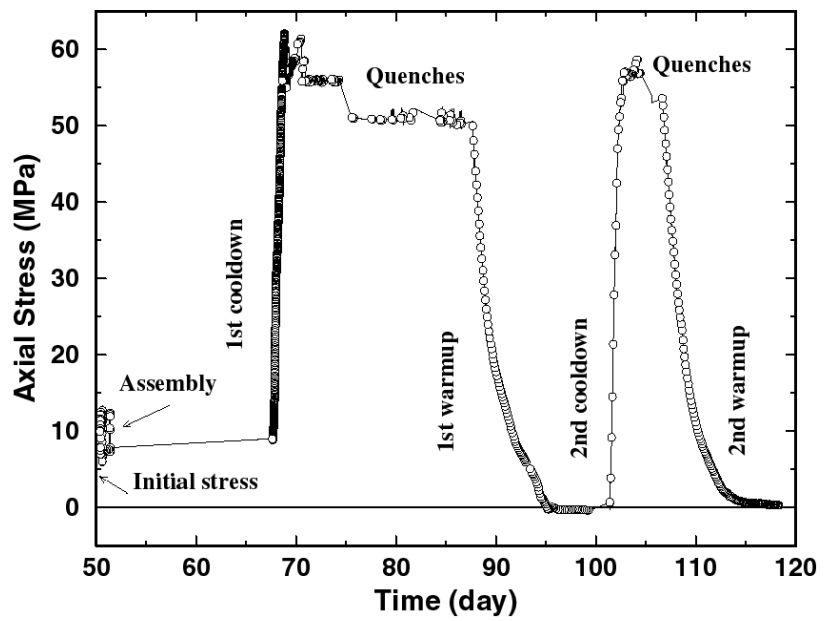

Fig. 8, Axial Stress in the Shell vs. time.

\section{ACKNOWLEDGMENT}

The authors would like to acknowledge the diligent work the mechanical and electrical technicians provided in support of this record-breaking effort.

\section{REFERENCES}

[1] S. A. Gourlay, et al., "Fabrication and Test Results of a Prototype, Nb3Sn Superconducting Racetrack Dipole Magnet," 1999 Particle Accelerator Conference, New York, NY, March, 1999.

[2] K. Chow, et al., "Mechanical Design of a High Field Common Coil Magnet," 1999 Particle Accelerator Conference, New York, NY, March, 1999.

[3] S.A. Gourlay, et al., "Design and Fabrication of a $14 \mathrm{~T}$, Nb3Sn Superconducting Racetrack Dipole Magnet," IEEE Transactions on Applied Superconductivity, Vol.10, pp. 294 - 297, 2000.

[4] S. Caspi, et al., "The Use of Bladders for Stress Control of superconducting Magnets," these proceedings.

[5] S. Caspi, M. Fong, S. Gourlay, R. Hafalia, A. Lietzke and J. O'Neill, "RD3 Structure," SC-MAG 725, Lawrence Berkeley National Laboratory, June, 2000.

[6] S. Gourlay et al., "Fabrication and Test Results of a Nb3Sn Superconducting Racetrack Dipole Magnet," Particle Accelerator Conference, New York, NY, 1999. 